\title{
Kaizen Perspective in Curriculum Development
}

\section{Volkan Duran ${ }^{\circledR}$ Hüseyin Mertol ${ }^{2}$}

${ }^{\prime}$ Psychology Department, Faculty of Science and Arts, I $\breve{g} d \imath r$ University, I $\breve{g} d \imath r$, Turkey Email:volkan.duran8@gmail.com Tel:4449447

${ }^{\circ}$ Geography Department, Faculty of Science and Arts,Tokat Gaziosmanpaşa University, Tokat, Turkey.

Email: husomero@yahoo.com Tel:( 0356)2521616

\section{Abstract}

Kaizen is the combination of the words kai (change) and zen (better) in Japanese. It means change for the better, continuous improvement (Albayrak, 2019). In Japan, Kaizen is a task for all staff and stakeholders. Kaizen can be regarded as the reflection of two different perspectives on management in terms of two distinct cultures. The difference between these two approaches is that the Western perspective focuses on the result of the premise while Japanese perspective zeroes on the process. While it is aimed to solve the problems by the stakeholders in different positions in terms of Western perspective, it is common to solve them together in Kaizen philosophy. This kind of habit of putting the hand under the stone has brought success in competition for Japan in business and manufacture. Hence, in this study it is aimed to investigate the basic principles of the Kaizen approach in terms of curriculum development and its principles, so the questions given as follows are sought: 1. What are the core principles of the Kaizen approach? 2. How the Kaizen approach is applied in different branches as well as education? 3. What kind of a curriculum development model can be suggested to improve the Kaizen approach in curriculum and development process? Therefore, Kaizen principles will be examined through document analysis technique in order to reveal core principles of it in the context of curriculum development models as well as proposing curriculum development model based on Kaizen approach. It can be inferred that the core principles of the Kaizen approach have many similarities and differences with curriculum and development approaches.

Keywords: Kaizen approach, Curriculum development, Curriculums.

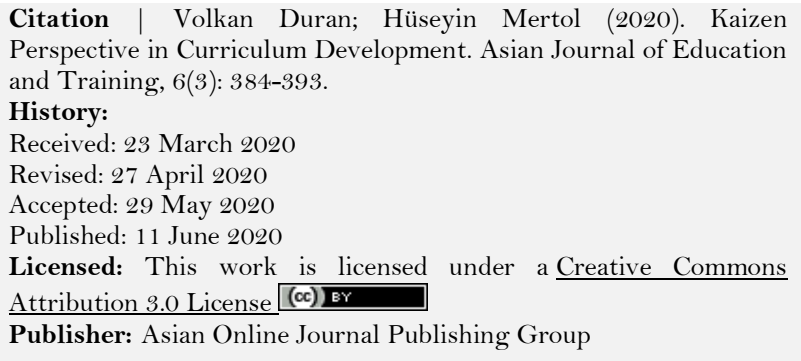
$\begin{array}{ll}\text { Attribution 3.0 License }(\mathrm{cc}) \text { EY } & \text { Ethical: This study follows all ethical } \\ \text { Publisher: Asian Online Journal Publishing Group } & \begin{array}{l}\text { Note: This paper was orally presented in } \\ \text { Instruction (ICCI-EPOK 2019) in Ankara }\end{array} \\ \text { Contents } & \end{array}$

Acknowledgement: Both authors contributed to the conception and design of the study.

Funding: This study received no specific financial support

Competing Interests: The authors declare that they have no conflict of interests.

Transparency: The authors confirm that the manuscript is an honest, accurate, and transparent account of the study was reported; that no vital features of the study have been omitted; and that any discrepancies from the features of the study have been omitted; and that any discrepancies from the

Note: This paper was orally presented in $7^{\text {th }}$ International Congress on Curriculum and

1. Introduction 


\section{Contribution of this paper to the literature}

This study presents a new perspective in curriculum development by considering Kaizen ideas and proposes a new curriculum development model in the context of Kaizen principles.

\section{Introduction}

Kaizen is the combination of the words kai (change) and zen (better) in Japanese. It means change for the better, continuous improvement. It covers activities involving senior managers, managers, and employees in work environments. Kaizen allows seeing problems and possible problems rather than content with the current situation (Albayrak, 2019). In Japan, Kaizen is a task for all staff and stakeholders. Kaizen can be regarded as the reflection of two different perspectives on management in terms of two distinct cultures. The difference between these two approaches is that the Western perspective focuses on the result of the premise while Japanese perspective zeroes on the process. While it is aimed to solve the problems by the stakeholders in different positions in terms of Western perspective, it is common to solve them together in Kaizen philosophy. This kind of habit of putting the hand under the stone has brought success in competition for Japan in business and manufacture sectors (Cakır, 2018; Doğanay, 2008; Erdeniz, 2018).

Demirel (2009) defined the curriculum development as the dynamic relationship between the objectives, content, learning-teaching process and evaluation elements of the educational program. In the context of this definition, Kaizen principles could be very useful for curriculum development. Additionally, when the similarities between Japanese culture and Turkish culture is taken into account by additionally considering the appropriateness of the Kaizen principles for curriculum development, it might be beneficiary to investigate the core principles of Kaizen approach and incorporate it in curriculum development in this regard. Hence, in this study it is aimed to investigate the basic principles of the Kaizen approach in terms of curriculum development and its principles so the questions given as follows are sought:

1- What are the core principles of the Kaizen approach?

2-What kind of a curriculum development model can be suggested to improve the Kaizen approach in curriculum and development process?

3-Why Kaizen approach is important for curriculum development?

\section{Method}

The study is a qualitative study based on a document analysis method. Document analysis involves the analysis of written materials containing information about any subject or the cases, a phenomenon that is targeted for investigation. Document analysis techniques in qualitative research data collection methods were used in the collection of research data (Bal, 2013; Creswell, 2012; Yıldırım \& Simşek, 2008). Therefore in this article, it is aimed to investigate the relevant texts related to kaizen approach through text analysis form developed by the researcher based on the research questions. In this context, relevant documents are defined as research texts containing kaizen approach and similar techniques in the historical process. Finally, in this research, it is aimed to synthesize data from the collected texts so that a synthesized conclusion can be given regarding the kaizen approach.

\section{Findings}

\subsection{Findings for the Second Question as "What are the Core Principles of the Kaizen Approach?"}

The fundamental starting point for the Kaizen philosophy, which expresses positive and continuous developme ntis that nothing is perfect and that it will always be achieved better (Karakaya, 2004). Kaizen is not a one-off, but an ongoing process. Since negative problems are always be expected to exist. Kaizen thus needs not only assistance, but also the collaboration and participation of the entire organization (Bozdemir \& Orhan, 2011). The theory of Kaizen suggests that we have to concentrate on continuous development activities, whether we are a t school, social life and home (Imai, 2014). For Kaizen approach, the process is important because in order for the good outcomes the processes must be good. The results of the continuous improvement work should not create a negative result for occupational safety, quality and cost. The activities to set advanced standards are to be improved. After the establishment of advanced standards, protection is needed for the application of new standards (Albayrak, 2019). Therefore, a standard is the first key too improvement. A standard is the best known way to perform a task (Coimbra, 2013). Therefore, there is a close relationship between setting standards and improvement in Figure 1.

It should be noted that there are different types of Kaizens depending on the needs and aims. For example, High-Impact Kaizen, focus on making dramatic improvements and solid inroads into revising the way production. Training and Implementation Kaizen, emphasize training the workforce over a span of time and making smaller but important changes. Problem Resolution Kaizen is aiming at resolving recurring production problems and putting them to bed permanently. Sustaining Kaizen, leads to make additional ongoing change to the initial improvements implemented in a high-impact and other types of formal Kaizen activity (Davis, 2011).

Besides to these approaches, different techniques can be used for the implementation of Kaizen activities. For example, PDCAs (plan-do-check-act or plan-do-check-adjust) can be regarded as four stages of management that are used by managers to track and enhance existing operations and goods. However, Kaizen approach have differences from techniques such as PDCA in terms of many respects. For instance, Kobetsu Kaizens are often identified by top management, teams are formed and goals are set. Problem solving tools are used and realized with the participation of employees from different departments. 7 steps for a Kobetsu Kaizen can be given as below. 


\section{Kaizen Standards: Standard Definition}

A standard is the first key to improvement. A standard is the best known way to perform a task.

The best way of having more predictable throughput is to set standards in all departments, measure problems against them and solve them.

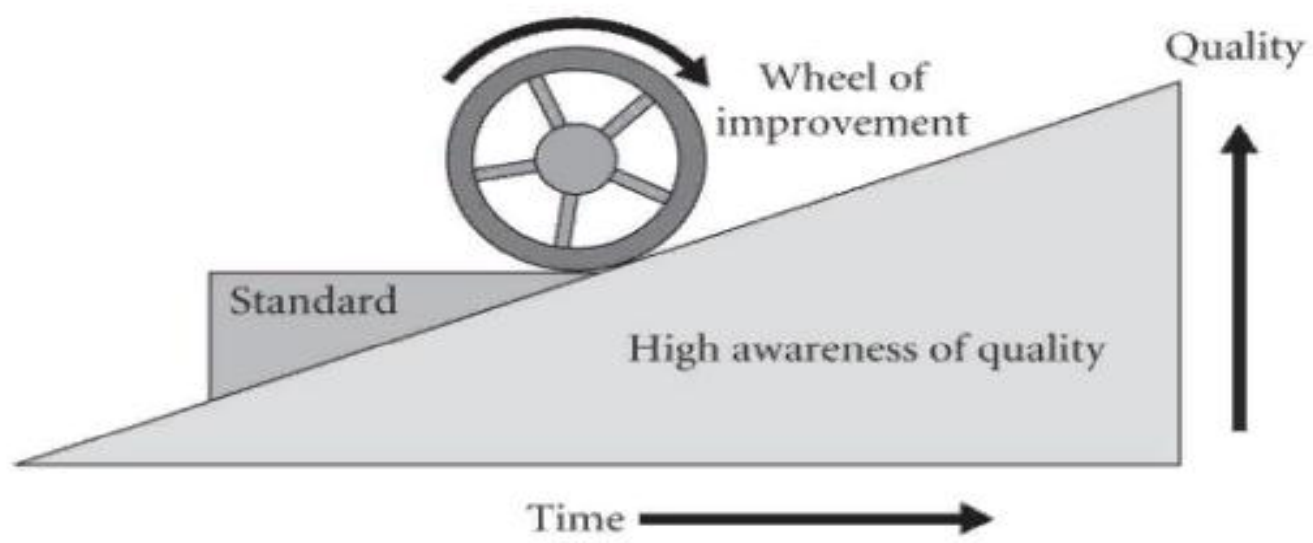

Any time improvements are made to a production area, strict adherence to standards is the key to both maintaining the performance of the line over time and increasing the performance in the future through continuous improvement systems!

Figure-1. There is a close relationship between setting standards and improvement.

Source: Coimbra (2013).

Table-1. Steps for Kobetsu Kaizen activities

\begin{tabular}{|c|c|c|}
\hline Steps & Details & Activity \\
\hline \multirow[t]{3}{*}{ Step 0} & \multirow[t]{3}{*}{ Select the improvement topic } & 1. Select and register the topic \\
\hline & & 2. $\quad$ Form Project teams \\
\hline & & Plan activities \\
\hline \multirow[t]{3}{*}{ Step 1} & \multirow[t]{3}{*}{ Understand the situation } & Identify the process \\
\hline & & Measure failures, defects and loses \\
\hline & & 3. Use baselines to set targets \\
\hline \multirow[t]{3}{*}{ Step 2} & \multirow[t]{3}{*}{ Expose and eliminate anomalies } & 1. Thoroughly study and expose anomalies \\
\hline & & 2. Restore deterioration and correct minor flaws \\
\hline & & 3. $\quad$ Establish basic equipment condition \\
\hline \multirow[t]{3}{*}{ Step 3} & \multirow[t]{3}{*}{ Analyze causes } & Stratify and analyze causes \\
\hline & & 2. Apply analytical techniques \\
\hline & & Conduct experiments \\
\hline \multirow[t]{3}{*}{ Step 4} & \multirow[t]{3}{*}{ Plan improvements } & 1. Make improvement proposals \\
\hline & & 2. Compare effectiveness of alternative proposals \\
\hline & & 3. Check for possible positive and negative effects \\
\hline \multirow[t]{3}{*}{ Step 5} & \multirow[t]{3}{*}{ Implement improvements } & 1. Carry out improvement plan \\
\hline & & 2. $\quad$ Perform tests, trial runs \\
\hline & & $\begin{array}{l}\text { Provide instructions to work on improved equipment } \\
\text { and operating conditions }\end{array}$ \\
\hline \multirow[t]{2}{*}{ Step 6} & \multirow[t]{2}{*}{ Check results } & 1. Evaluate results over a set period \\
\hline & & 2. Check whether the targets have been achived \\
\hline \multirow[t]{2}{*}{ Step 7} & \multirow[t]{2}{*}{ Consolidate gains } & Prepare inspections and work standards \\
\hline & & 2. Make drawings and feed information to manegement \\
\hline
\end{tabular}

Source: https://www.tpmclubsa.co.za/wp-content/uploads/2013/07/kobetsu_kaizen.pdf retrieved from 09.12.19.

When these steps were examined in Table 1, it can be seen that first step is to select an improvement topic. This phase includes also to form project teams and to plan activities. Second phase is to understand the situation by identifying the situation and determining the failures to propose goals. Third phase is to expose and eliminate abnormalities so that more "clean" form of state can be reached. Waste elimination is the first pull-flow-related kaizen principle. Kaizen defines seven forms of waste and targets their elimination as a way of achieving competitiveness and excellence. These seven wastes include (Coimbra, 2013):

1. Defects (internal or external failures of quality).

2. People waiting.

3. People moving.

4. Too much processing.

5. Material waiting.

6. Material moving.

7. Overproduction.

Fourth phase it to analyze causes by applying analytical techniques as well as empirical experiments. Fifth phase is to plan improvement in order to remedy and to develop situation in a positive or better way. Sixth phase includes to implement the improvements to test whether the proposed improvements work or not. Therefore, seventh phase is about checking results to observe whether the targets have been achieved. Finally, giving feed backs to consolidate gains by making drawings and feeding information to management is the last step for a Kobetsu Kaizen. 
In this respect first principle of the Kaizen is the continuous and systematic development for a given system. While Kaizen's improvements are small and gradual, the Kaizen process produces dramatic results over time. The c oncept of kaizen explains why businesses in Japan can not stay static for long (Imai, 2014). However, it should be outlined that such a continuous development can be actualized only by the action of humans. The focus is on human endeavors in Kaizen. In all processes, people have influence and intervention positively or negatively in the process. The positive ones are labelled as improvements affecting the outcomes (Akil, 2013). Hence, the second principle of the kaizen is to focus on human intervention which is sometimes mentioned in the literature as agency but this agency is not limited to teachers but the whole stakeholders and participants of the system.

Thirdly, because human intervention is important in Kaizen approach, each stakeholder needs to be part of ongoing improvement. The expertise of the stakeholders in solving problems should be strengthened, problems should become solvable and systematic rather than seasonal. Hence, holistic participation of all parties are of having significance for the Kaizen approach. Not only teachers or students are the part of the process but also parents and all other parties should be engaged in this process in an educational sense.

Fourthly, Kaizen approach focuses on the process rather than the outcomes. The goal of the individuals in this process is to generate ideas and new initiatives and ventures on how to strengthen and expand their own duties or aims. Today many educational theories also emphasize the similar approaches in line with Kaizen approach. They stresses authentic learning allowing the learners, in ways involving the real-world problems and tasks that are important for the learner, to explore, analyze and construct meaningfully ideas and relationships. A processoriented approach should be applied in the introduction of the various kaizen strategies: the plan-do-check-act (PDCA) cycle; the standardize-do-check-act (SDCA) cycle; quality, cost, and delivery (QCD); total quality management (TQM); just-in-time (JIT); and total productive maintenance (TPM) (Imai, 2014).

Fifthly, Kaizen approach doesn't satify the current situation wherever it is. There is a way to be found even in perfectly executed systems. The system is never perfect. The existing system should be continuously moved forward in small steps. Therefore, there is no one as perfect or bad in such a philosophy but conditions that should be improved.

Sixthly, accepting the problem is one of the important aspects of Kaizen approach. The concept of problem, which is a military term originating from Greek, covers all situations that disturb the individual physically or cognitively. Therefore, if someone has a problem, s/he has a some sort of disturbing obstacle, if there is no problem, there are reliefs that make people inactive or be happy about the situation.

Seventhly, proper problem solution techniques should be used for the current problems. These might be statistical tools and techniques that provide problem-solving methods; histograms, control tables, scatter diagrams, cause and effect diagrams, graphs, control charts and pareto diagrams.

Finally, the economic or other achivements shouldn't be a priority. For instance, PISA scores shouldn't be the main aim for education system. For instance, according to PISA (2018) science scores, Israel falls back to Turkey in science branch. However, when considering the fact that at least 20\% Nobel Prize winners are Jews and the scientific contribution of the Israel are taking into account, it can be seen that PISA results couldn't be regarded as the only measure for defining the success of education.

The basic principle of Kaizen is: "The best is the enemy of the good". Rather than find and solve the problem of classical understanding, it adopts to identify potential areas that may be problematic and to take precautions (Söztanac1, 2014). Kaizen approach can be used in any field because complex techniques and large investments are not required to implement Kaizen. Only simple techniques like problem solving tools and dedication to work with constant effort are required whereas innovation requires advanced technology and large investments (Yılmaz, 2014). Kaizen outlines the small improvements that the ongoing efforts have seen. In order to achieve this, it is very important to ensure the participation of all personnel by giving priority to the administrators and to create a permanent and regular structure through gradual progress. Innovation requires the product of large investments in new technology and/or equipment, that is the drastic change of the current situation. Because Kaizen is a continuous process which involves everyone in the company, all hierarchical employees have to be interconnected with kaizen. In innovation, however, individual efforts and creativity are gained more significance in this regard Figure 2 (Kesken \& Ilic, 2008).

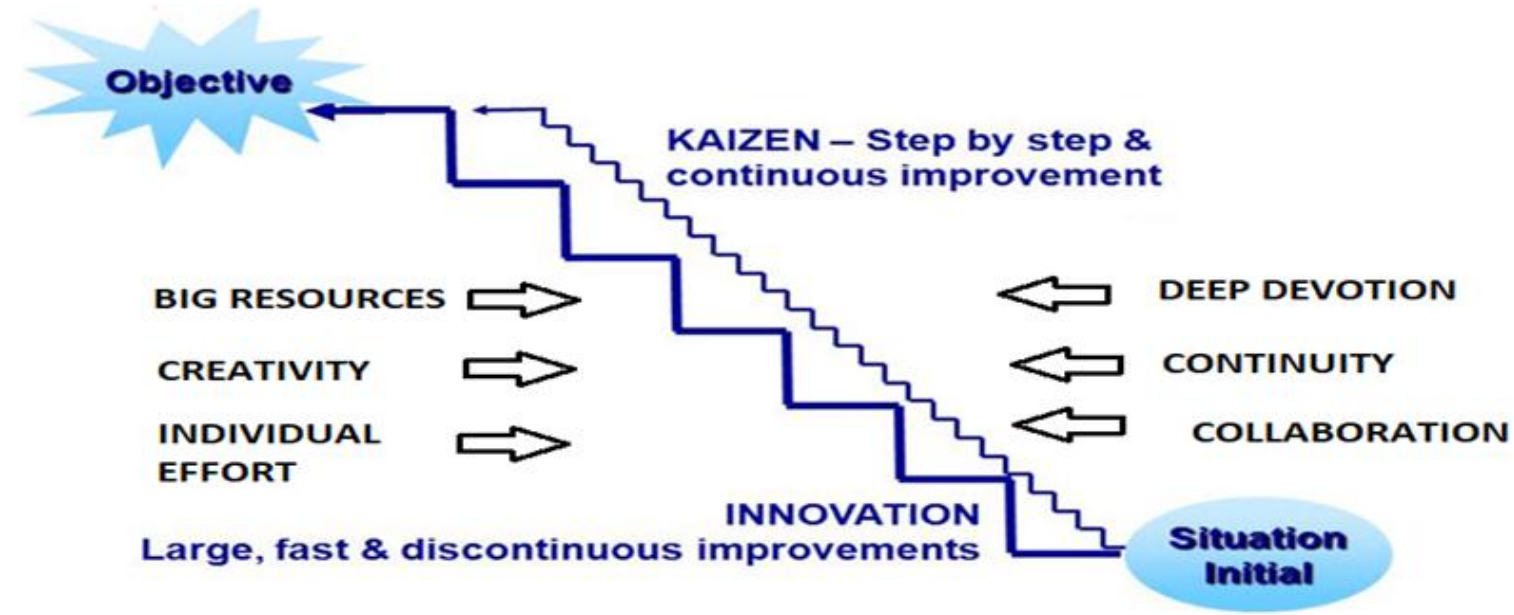

Figure-2. Kaizen approach focus on deep devotion, continuity and collaboration whereas innovation stress big resources, creativity and individual efforts.

Therefore, kaizen's true meaning is to encourage people to improve any aspect of their life, to become motivated and instantly incorporate these ideas (not just their work), into their community. This is Kaizen's leverage: it is resilient and flexible as it is a personal commitment and everybody can bring his vision into action (McLoughlin \& Miura, 2018). To summarize: 
1- Kaizen is the continuous and systematic development for a given system.

2- Kaizen philosophy focus on human intervention or human agency.

3- Holistic participation of all parties are of having significance for Kaizen approach.

4- Kaizen philosophy focus on process rather than end products.

5- Kaizen approach doesn't satisfy the current situation wherever it is. Therefore, there is no perfect level in Kaizen approach but there are amendable states.

6- Accepting the problem is the important aspect of Kaizen approach.

7- $\quad$ Proper problem solution techniques should be used for the current problems.

8- The economic or other achievements shouldn't be a priority.

Hence building a real-life Kaizen workflow system is essential to Davis (2011); Ogünç and Doğru (2017):

1. Understand through Kaizen forms and when and how they should be used. principles.

2. Develop a well-structured training and execution process for the implementation of Kaizen

3. Driving Kaizen thinking through the rank and file.

4.. Create a high level of support and enthusiasm in the top ranks.

5. Kaizen's work should include a leadership or voluntary staff assigned to do so. feasible.

6. Although Kaizen is seen as an individual-based improvement, teamwork is required to make it

7. In order to be aware of the problems, awareness of the personnel must be formed and kaizen training must be done for this.

8. In order to increase the efficiency of kaizen activities, kaizens obtained should be announced to all personnel through meetings and different activities.

9. Motivating, encouraging, rewarding or appreciation of the staff who make kaizen should be ensured for Kaizen activities.

\subsection{Findings for the Second Question as "What Kind of a Curriculum Development Model Can be Suggested to Improve the Kaizen Approach in Curriculum and Development Process?”}

Kaizen approach is used many branches especially in business as well as human resources in hospitals and education. For instance, kaizen costing was used for cost efficiency where kaizen costing refers a technique which aims to continuously improve the production processes in order to achieve this target cost by determining a target cost and to ensure cost effectiveness, and it is regarded as a technique which is used to reduce the costs and continuously monitor the cost reductions at every stage of production. Kaizen costing is used accommodation enterprise, air cargo enterprises, cost minimization (Alatas, 2015; Cakır, 2018; Macit, 2018; Terzi, 2017). Kaizen suggestion system was also used for increasing job security in which all employees were given the necessary trainings and the kaizen suggestion forms developed for the company were used and evaluated (Söztanac1, 2014). It can be used also in continuous improvement development of human resources in hospitals where patient focus, process improvement and employee empowerment are main principles (Y1lmaz, 2014). Kaizen approach is used for improving the quality of final product in manufacturing sector (Korucu, 2013). It can be used in low cost and high quality product/service in public sector (Akıl, 2013). As it can be seen, in many areas Kaizen approach can be used. Therefore, Kaizen principles can be used in also education and curriculum development area because the aim of the Kaizen is continuous improvement in any given system by human collaboration and endeavor.

In the context of kaizen, management has two major functions: maintenance and improvement. Maintenance emphasizes the practices aimed at preserving and enforcing current standards of technology, leadership and service through training and discipline. Meanwhile, improvement applies to practices aimed at improving current standards (Imai, 2014). Therefore, curriculum can be conceived in terms of two aspects as improvement and maintenance in the context of kaizen approach given as in Figure 3. Improvement begins from students to ministry education vice versa and maintenance is achieved from hidden curriculum to formal curriculum supported by null curriculum, extra curriculum and informal curriculum. Formal curriculum refers to "the planned program of objectives, content, learning experiences, resources and assessment offered by a school.". Informal curriculum indicates co-curricular activities which happen outside of formal educational environment the content of the formal curriculum. Extra-curriculum includes the nonobligatory activities for the pupils. Extracurriculum is important for Kaizen because it is related with the value-adding activities and subjects. Null curriculum covers topics omitted as unimportant from the formal curriculum. Null curriculum is of having significance for Kaizen because it is related with activities that do not add value but should be carried out and the activities seen as waste. Finally, hidden curriculum covers the values which are transferred by social relationships and teachers in school setting that are not explicitly emphasized (Arslan \& Akbulut, 2018; Posner, 1995).

FORMAL CURRICULUM

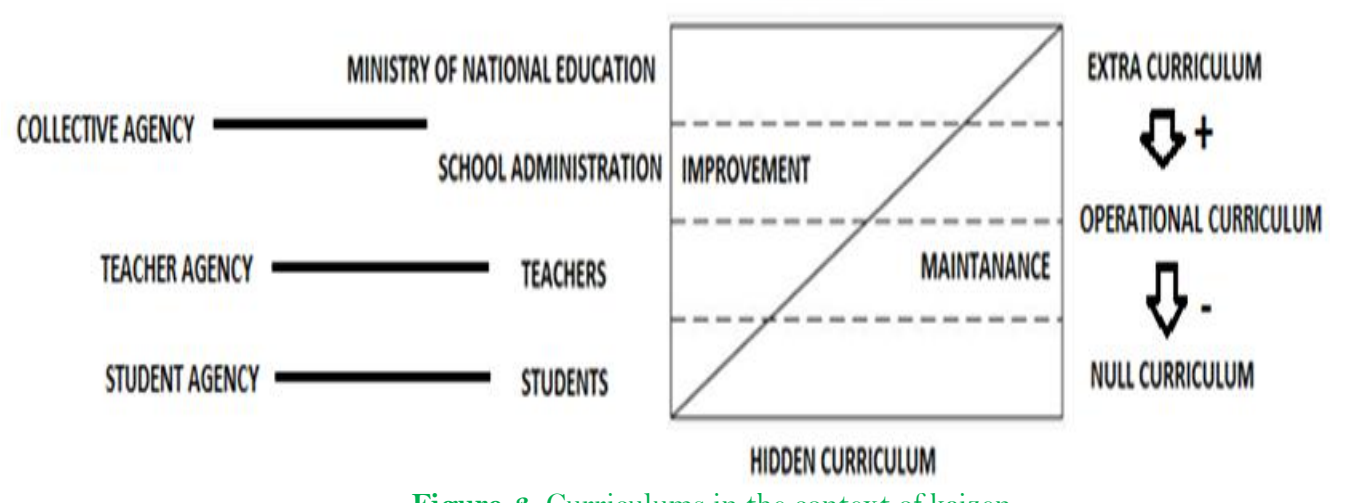

Source: Modified from Imai (2014).

Figure-3. Curriculums in the context of kaizen. 
In Turkey, it seems that there are problems in the improvement and maintenance of curriculums from formal curriculum to hidden curriculum in many aspects. In the context of formal curriculum (official curriculum), it should be prepared as a theoretical and framework by considering the social part of curriculum from Ministry of National Education to Students based on the Kaizen principles. Therefore, the roles of stakeholders as students, teachers, school administration as well as ministry of national education are the important part of the improvement of the formal curriculum.

Unless the maintanance is fully aligned and capable of supporting the initiative, kaizen should never be done. T his ensures that the tools and materials necessary for transition can be quickly and effectively rendered at the dispo sal of the participating team (Davis, 2011). The roles of all stakeholders for the maintenance of the curriculum, in this regard, can be given as Table 2 below. This table shows that Kaizen approach gives responsibilities all stakeholders in the curriculum development process. It should be noted that kaizen proposals which are formulated without all stakeholders' opinions would probably fail altogether or will need to be updated later if introduced. Without the cooperation of all stakeholders in a given area, true Kaizen cannot be achieved (McLoughlin \& Miura, 2018).

Table-2. Participation hierarchy for the application of Kaizen in curriculum development

\begin{tabular}{|c|c|c|c|}
\hline $\begin{array}{l}\text { Ministry of national } \\
\text { education }\end{array}$ & School administration & Teachers & Students \\
\hline $\begin{array}{l}\text { It is committed to } \\
\text { launching Kaizen as a } \\
\text { strategy. }\end{array}$ & $\begin{array}{l}\text { It disseminates and executes } \\
\text { kaizen objectives through } \\
\text { policy extension and cross- } \\
\text { functional activities as } \\
\text { determined by senior } \\
\text { management. }\end{array}$ & $\begin{array}{l}\text { Uses Kaizen in functional } \\
\text { roles }\end{array}$ & $\begin{array}{l}\text { Participates in Kaizen } \\
\text { with suggestion system } \\
\text { and small group } \\
\text { activities }\end{array}$ \\
\hline $\begin{array}{l}\text { Provides support and } \\
\text { direction to Kaizen by } \\
\text { providing resources. } \\
\end{array}$ & $\begin{array}{l}\text { Uses Kaizen in functional } \\
\text { activities. }\end{array}$ & $\begin{array}{l}\text { Prepares and guides } \\
\text { students }\end{array}$ & $\begin{array}{l}\text { Follows discipline in the } \\
\text { schools }\end{array}$ \\
\hline $\begin{array}{l}\text { Creates policy and cross- } \\
\text { functional objectives for } \\
\text { Kaizen. }\end{array}$ & $\begin{array}{l}\text { Set, maintain and improve } \\
\text { standards. }\end{array}$ & $\begin{array}{l}\text { Strengthens communication } \\
\text { with students and provides } \\
\text { high morale }\end{array}$ & $\begin{array}{l}\text { Continuously improves } \\
\text { themselves to better } \\
\text { solve problems }\end{array}$ \\
\hline $\begin{array}{l}\text { It conducts policy } \\
\text { dissemination and audits } \\
\text { to achieve Kaizen } \\
\text { objectives. }\end{array}$ & $\begin{array}{l}\text { Implements Kaizen } \\
\text { awareness to employees } \\
\text { through training programs }\end{array}$ & $\begin{array}{l}\text { Supports small group work } \\
\text { and individual suggestion } \\
\text { systems such as quality } \\
\text { circles }\end{array}$ & \multirow[t]{2}{*}{$\begin{array}{l}\text { Improves talent and } \\
\text { experience with cross- } \\
\text { training activities }\end{array}$} \\
\hline $\begin{array}{l}\text { Build systems, processes } \\
\text { and structures for } \\
\text { Kaizen. }\end{array}$ & $\begin{array}{l}\text { Helps employees develop } \\
\text { skills and problem-solving } \\
\text { tools }\end{array}$ & Creates Kaizen suggestions & \\
\hline
\end{tabular}

Source: Modified from Imai (2014)

When the table above is investigated, unless the right people are involved, Kaizen should never be carried out. The right people involve the establishment of a cross-functional group of participants and some of whom have complete decision-making powers without anybody's approval (Davis, 2011). It can also be seen that the concept of agency is emphasized in three levels as student agency, teacher agency and collective agency Figure 3. Generally, the concept of agency refers "the capacity for deliberation or even a special kind of knowledge of one's actions" (Misselhorn, 2015). The concept of agency refers to individual's ability to behave on its own and make free choices. At the very least the term 'agent' implies (1) an individual, and (2) a capacity for action (Stapleton \& Froese, 2015). However, it should be noted that there are structural factors that determine or restrict an individual and its actions, such as social class, ideology, gender, race, skill, traditions, etc. However, agency is a significant factor for all the levels of the improvement of curriculum from students to teachers to the institutions. Student agency refers the individual agency implying that human agents are conscious on their own choices (Gabbay \& Woods, 2005) as well as it gives students an active role in seeking and internalizing new knowledge (Zeiser, Scholz, \& Cirks, 2018). In many modern learning theories, it is emphasized that teaching process should be student-centered rather than teacher or content centered. However, the term student-centered is often used as a concept indicating for the arrangement of the activities in the classrooms where students are more active and independent but leaving blank how students are motivated and be an active agent of their own learnings. Teaching without student agency and student motivation is as vain as any other "modern techniques" proposed by modern educational approaches such as constructivism. "Student agency refers to the quality of students' self-reflective and intentional action and interaction with their surroundings by including concepts of agentic possibility ("power") and agentic orientation (“will”)." Klemenčı̌ (2015). In this regard, it should be noted that Kaizen approach stress student agency not student authority. Kaizen approach ensures the students should possibly be "agents" in order to have an influence on their employment, their future lives and their immediate and larger social setting (Klemenčč, 2015).

Second important factor for the improvement of the curriculum is the teacher agency which considers teachers as "actors acting by-means-of-an-environment rather than simply in an environment" (Biesta \& Tedder, 2006). Teacher agency in this regard can be viewed in terms of dimensions proposed by The Triadic Reciprocity Framework Core Agency Concepts (TRFCAC) model as self-reactiveness (self-regulations, choices, action plans, implementation, reflections) self-reflectiveness (self-examining), intentionality (self-organizing, indications for change, action plans and strategies), forethought (visualizing futures, proactive) (Jenkins, 2019). Due to the fact that Kaizen approach emphasizes human efforts, morale, involvement, and self-discipline (Imai, 2014) it also support positive student and teacher agency in this respect.

Finally, Kaizen approach underlines the concept of collective agency in order for the improvement of curriculum as well as the actualization of student and teacher agency because without collective agency, all other agencies are individual efforts that are on hiding to nothing. All agency types and all agents act by direct or 
indirect intervention or other agents and agencies so that they are not autonomous in this respect but they are autonomous by being able to change their state without direct response to interaction through performing internal transitions to change their states (Floridi \& Sanders, 2004; Misselhorn, 2015). Collective agency refers to a social state where individuals try to work together to achieve what they cannot achieve by themselves (Johnson \& Johnson, 2015). It requires collective synchronization, coordination, mutual cooperation as well as collective goal resulting in collective goal-directed behavior in which the actions of the individual agents must be directed at the same goal, and their behavior must be coordinated in a specific ways in terms of behavioral and cognitive dimension (Misselhorn, 2015).

In the context of the concept of agency, it can be easily concluded that formal curriculum shouldn't be taken as sole factor for maintenance of a curriculum based on Kaizen principles. The other curriculum types proposed by Posner (1995) come to fore for such a maintenance based on Kaizen principles so that different agency types can be actualized from individualistic level to collective phase. Operational curriculum is the place where the formal curriculum is actualized. Therefore, Kaizen principles can be actualized in the teacher's hands, because the operational curriculum is concerned with the teacher's understanding and perception of the formal program and is closely related to the teacher's training and competences. It is mainly related with the teacher agency so that maintenance of the curriculum can be actualized. In this type of program, the teacher perceives and conveys the activities in the united annual plans and lesson plans, and the students are supposed to receive them. At this point, it can be predicted that improvements in teacher competencies in the program process will make positive contributions for the actualization of Kaizen principles in the official curriculum.

Extra curriculum refers to the planned activities outside the formal curriculum. The extra curriculum includes activities outside the official program, including musical, educational, cultural and sporting activities. In this way it can be used in developing conditions that cannot be foreseen by or distinguished by the official scheme, since it is the informal involvement that is voluntary and open to all students and thus improves the student agency. Therefore, it provides flexibility to the maintenance of curriculum in the context of Kaizen principles.

Another type of curriculum in which the actualization of Kaizen principles might be neglected is the null curriculum. This curriculum refers the curriculum subjects which is in the official program that are skipped. Infrastructural problems in the schools is the main cause of the emergence of this type curriculum. Null curriculum can be a threat for the maintenance of the curriculum therefore required infrastructural changes should be provided.

Finally, another type of program that can play both positive and negative role in the actualization of the curriculum is the hidden curriculum. This type of curriculum, which is affected from the school climate and culture, also reflects informal learning about values, attitudes and beliefs that are not included in the official program. There might be positive and negative aspect of the hidden curriculum that can both provide dynamism as well as obstacles for the actualization of the curriculum. Therefore, if it is desired that Kaizen principles should be implemented in the curriculums, field works should be conducted on the basis of school types, regions and even individual bases as well as particular schools.

As for the Kaizen implementation, there are six steps for developing Kaizen in different levels of the curriculum development Figure 4. First step is to Discover the Improvement Potential referring to help students, teachers and administrators to learn to look more specifically at the problems and the potential improvement around them. Second step given as Analyze the Current Methods indicates to teach people how to conduct simple learning and teaching methods analysis. The third step for the implementation of Kaizen is to generate original ideas implying to help people start creating original ideas for improvement. Fourth step of the Kaizen is to Develop An Implementation Plan including "just-do-it" type of thinking, or plans required more coordination and careful thought. Fifth step is to Implement the Plan indicating the actualization of the plan as well as Kaizen principles. Sixth step is to Evaluate the New Method in which mistakes and recommendations are addressed depending on our shared expertise (Kato \& Smalley, 2015).

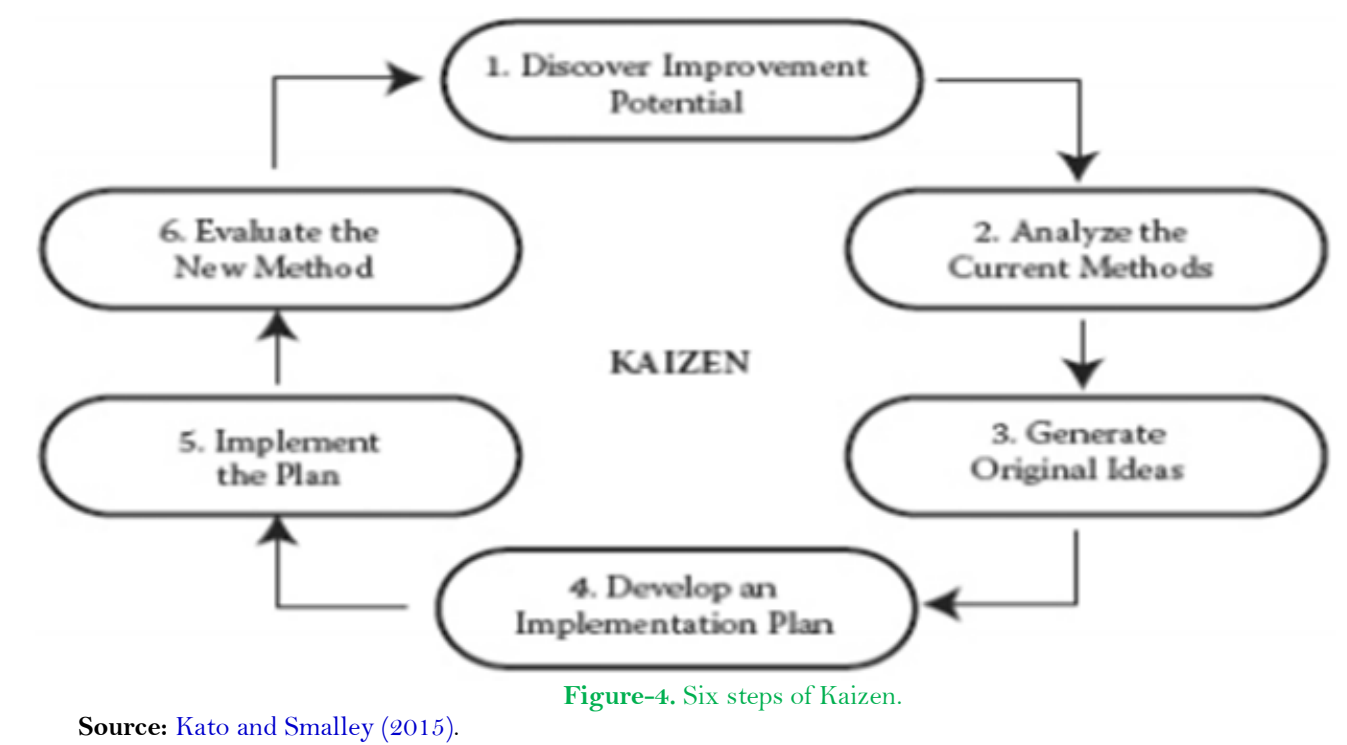

For the internal and external evaluation of the curriculum development process, a process-oriented approach also should be applied in the introduction of the various kaizen strategies: the plan-do-check-act (PDCA) cycle; the standardize-do-check-act (SDCA) cycle; quality, cost, and delivery (QCD); total quality management (TQM); justin-time (JIT); and total productive maintenance (TPM) (Imai, 2014). In this respect, the plan-do-check-act (PDCA) cycle as a vehicle that ensures the continuity of kaizen in providing a strategy for maintaining and improving standards of the curriculum development. Actually, the two core scientific methods of PDCA and SDCA represent 
the heart of what may be considered a "kaizen system." The system see Figure 5 is holistic and includes an underlying Philosophy including principles as follows (Hamel, 2010):

1. Think PDCA and SDCA, the basic scientific methods.

2. Go to gemba, observe and document reality.

3. Ask "why?" five times to identify the root causes.

4. Be dissatisfied with the status quo.

5. Kaizen what matters.

6. Have a bias for action.

7. Frequent, small incremental improvements drive big, sustainable improvements.

8. Use creativity before capital.

9. Kaizen is everyone's job.

10. No transformation without transformation leadership.

11. Do everything humility and respect for the individual.

This is the system of the various methods applied; their order in thought or action. Some methods can be given as follows:

1. Scientific (how to think).

2. Focus and alignment (where and when to apply).

3. Deployment vehicles (how to do it).

Tools can be defined as the various lean and, as appropriate, six sigma techniques employed in the methods. Cultural enablers are the organization's distinctive behavior patterns, founded upon humility and respect for the individual, facilitate and encourage continuous improvement (Hamel, 2010):

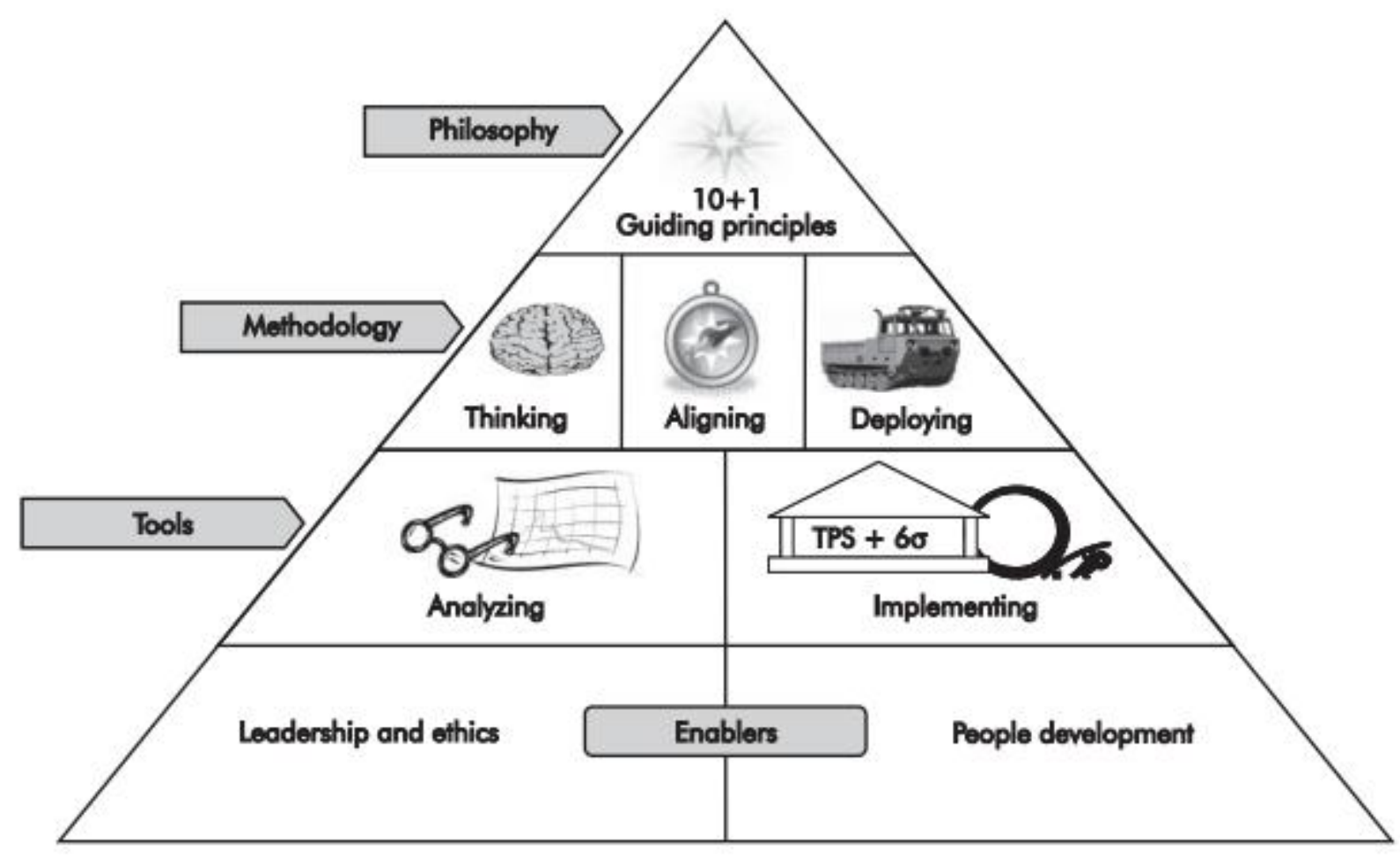

Source: Hamel (2010)

Figure-5. The Kaizen system.

Plan refers to establishing general aims for improvement of the curriculum. Decisions to be taken in planning phase should be based on real data and realistic when determining work or goals. Initially, if very high targets are set and they are not achieved, motivation will decrease and inefficiency will begin (Korucu, 2013). Additionally, it includes I- Creating program development working groups, II- Program development work plan III- Arranging required infrastructure and materials for the curriculum development process. A detailed needs evaluation is also key to any type of planning. An comprehensive needs assessment is a form of systematic decision-making and is the first phase of continuous improvement preparation (Education Quality and Continuous Improvement Framework, 2018). At this stage, identification of research design and data collection methods for evaluation purposes, determination of which measurement tools will be used for what purposes, when, how and how many times, and the validity and reliability studies of these tools are included (Fitzpatrick et. all, 2004, cited by Ozdemir (2009). It includes those steps (Education Quality and Continuous Improvement Framework, 2018; Kaya, 1997):

1) Confirmation of meaning (revealing what program evaluation means).

2) Determination of the purpose and shared vision.

3) Identification of key parties and collaborative stakeholders.

4) Identification of opportunities and barriers as well as problems.

5) Determining the questions to be answered and root cause analysis results.

6) Defining the theory of improvement/action for this goal.

7) Determining ideas for change.

6) Finalization of the draft.

Do refers to implementing the plan (Imai, 2014). It corresponds to collecting the data from various sources for needs analysis as well as the preparation of other researches. In this stage, research design, population and sample selection, data collection, analysis and interpretation of results are carried out in accordance with the decisions taken during the planning stage, and evaluation is reported (Fitzpatrick et. all, 2004 cited by Ozdemir (2009). 
Check refers to determining to whether the implementation is on schedule and the expected change has occurred (Imai, 2014). It corresponds to Analysis of the results and providing feedback for it. The aim of this course is to reveal the deficiencies and errors in the evaluation process. This process is also called "meta-evaluation (Fitzpatrick et. all, 2004 cited by Ozdemir (2009). 5S can be used as technique in the check process as well as the other phases of PDCA Figure 7; because it is used to improve total quality management processes referring as a strategy to create effective, efficient, flexible, competitive, and comprehensive changes (Goetsch \& Davis, 2002). With this technique, it is possible to establish, maintain a quality environment within the organization and solve many daily problems. It refers to Sort (Seiri), Straighten (Seiton), Scrub (Seiso), Standardization (Seiketsu) and Sustain (Shitsuke) in continuous check and improvement process Figure 6.

Seiri (Sort) refers to maintain the items needed in work areas, arrange or maintain less frequently used items within a remote storage area, discard unnecessary items. In another words, Seiri or classification consists of removing all those elements which are not required to perform the job from the area or educational fields. Seiton (Straighten) refers to systematic arrangement in a way providing the most efficient workflow, Order follows classification and organization. There would be hardly an outcome if things were marked, but not ordered. Therefore it is necessary to follow simple rules. Seiso (Shining) means to sweep and keep clean, tidy and ordered the office and all appliances. Seiso involves the construction of software that avoid, or mitigate, dirt and improve the protection of workstations. Seiketsu (Standardizing) refers to reliable and organized work practices. Seiketsu is intended to ensure organization, or standardization. Shitsuke (Sustaining) relates to keeping focus on the new way and does not encourage the old ways to decline gradually once the previous 4 Ss were created. Shitksuke aims at sustaining already established procedures (García-Alcaraz, Oropesa-Vento, \& Maldonado-Macías, 2017).

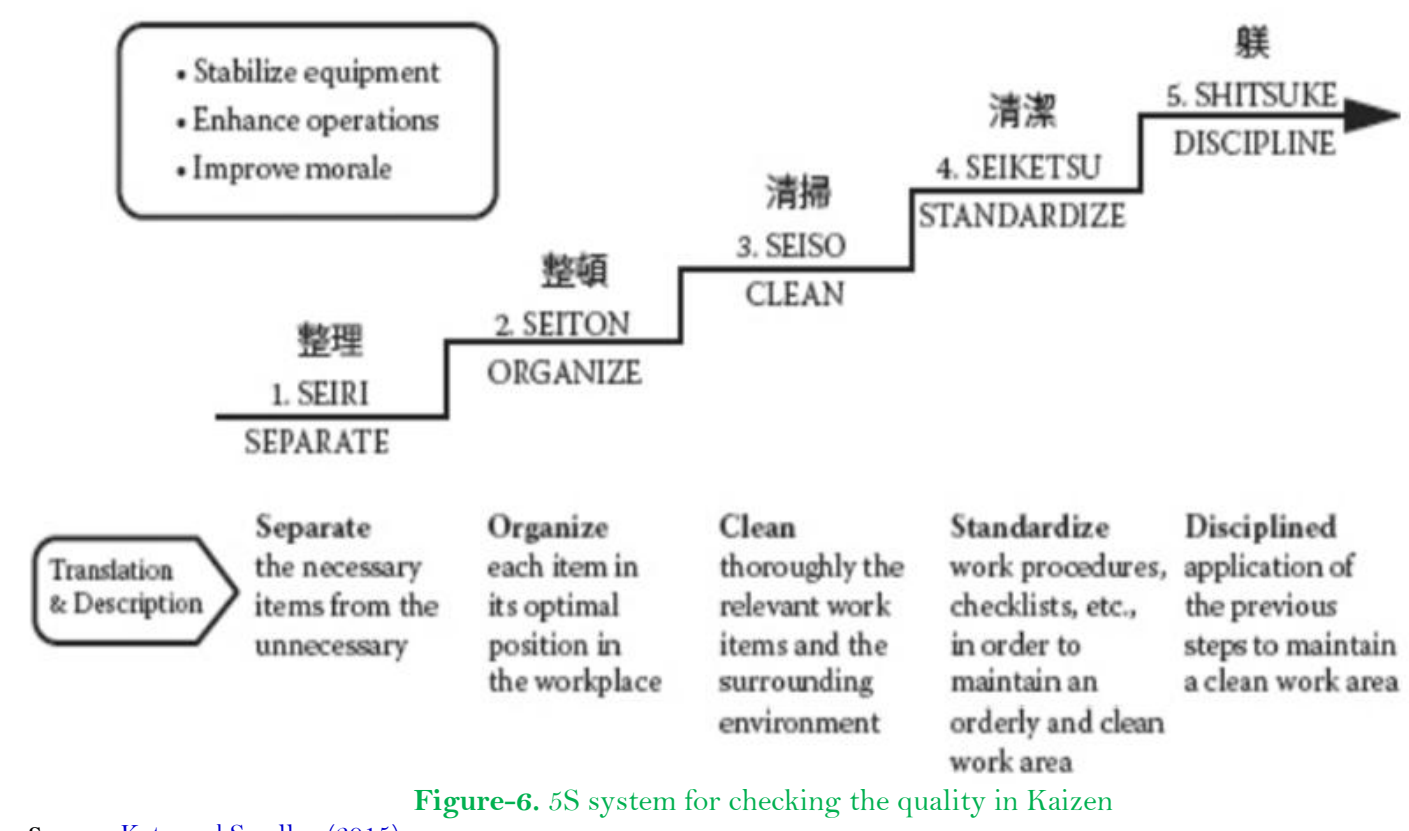

Source:: Kato and Smalley (2015).

The Act applies to the adoption and standardization of the new procedures to ensure that the original problem does not recur or to establish goals for new improvements (Imai, 2014). It includes implementation of the changes, monitoring the changes and comparing the results, review of information. Kaizen events are important in this phase. Kaizen events are formalized practices organizations use to quickly and significantly develop its community (Kaikaku). Kaizen events create a structured environment in which employees know how to define and use other lean tools to remove waste, faster turnaround, improved productivity, better quality, and reduced expenses (Martin \& Osterling, 2007).

\begin{tabular}{|l|l|}
\hline POCA (Deming Cycle) & $\begin{array}{l}\text { Macro-level PDCA } \\
\text { (Entire Kaizen Event Process) }\end{array}$ \\
\hline $\begin{array}{l}\text { Plar. Determine process objectives } \\
\text { and methods for achieving them }\end{array}$ & $\begin{array}{l}\text { Plan and prepare for the Kaizen } \\
\text { Event; obtain baseline data as } \\
\text { needed }\end{array}$ \\
\hline $\begin{array}{l}\text { Da. Design and implement } \\
\text { improvements, train workers }\end{array}$ & $\begin{array}{l}\text { Observe and analyze the current } \\
\text { process; design the improved } \\
\text { process; test, standardize and } \\
\text { document the new process; train } \\
\text { workforce }\end{array}$ \\
\hline $\begin{array}{l}\text { Check Measure the impact of the } \\
\text { improvements }\end{array}$ & $\begin{array}{l}\text { Monitor process performance; } \\
\text { conduct 30-day audit }\end{array}$ \\
\hline $\begin{array}{l}\text { Act Make further improvements as } \\
\text { necessary by repeating the } \\
\text { PDCA cycle }\end{array}$ & $\begin{array}{l}\text { Evaluate process performance, } \\
\text { compare with Value Stream } \\
\text { objectives, make further } \\
\text { improvements as needed }\end{array}$ \\
\hline
\end{tabular}

Source: Boca (2011) and Martin and Osterling (2007). 
Curriculum evaluation is undertaken to support the development off curriculum innovation, implementation or development and the program evaluation is aimed at ensuring the continuity of the program.

Furthermore, the curriculum evaluation has different objectives including knowing how to develop a program or procedure to show the efficiency and effectiveness gained by applying the system (Ozdemir, 2009). As a product of ongoing efforts, Kaizen reflects small improvements. As a result of significant resources investment $\mathrm{s}$ in new equipment or technology, innovation involves a drastic improvement. Therefore Kaizen is related with long-term benefits by emphasizing human efforts, morale, communication, training, teamwork, involvement, and self-discipline - a commonsense (Imai, 2014). Therefore, improvement as a concept can be broken down into innovation and kaizen. In this respect, innovation can be actualized by collective agency, Kaizen can be actualized by teacher and student agency. As it can be seen Figure 8 below, maintenance is achieved mostly by students, teachers.

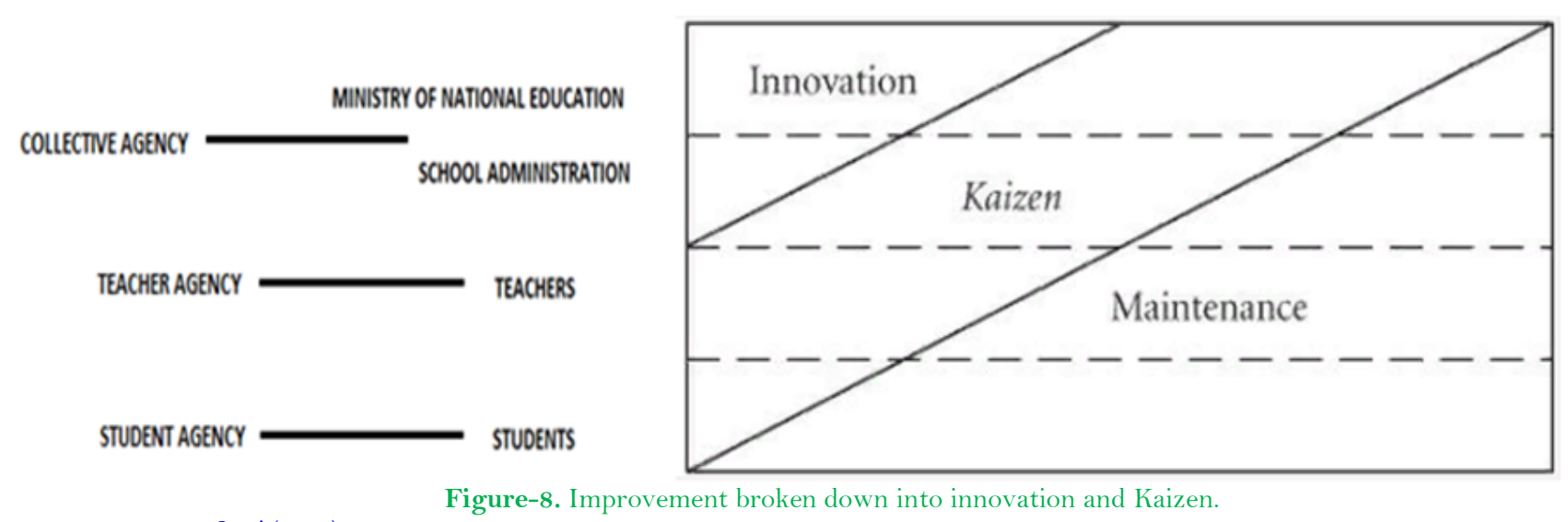

Source: Imai (2014).

Studies have suggested that organizations need a reasonable and scalable mechanism at the smallest level to ensure successful implementations in harmony with the frontline supervisor. It is difficult to transfer senior managers ' high-level purpose (general aims of the collective agency) to frontline teachers and students. A technique for this has been established in the Japanese management system named Hoshin Kanri. The Hoshin System outlines the Japanese approach for all stages of preparation and execution (McLoughlin \& Miura, 2018). For new habits to be adopted, everyone in,for instance, a company, from top management to the shop floor, needs to be involved. The way to do it is by organizing kaizen-focused teams. Developing people through teamwork is one of the strongest principles of kaizen (Coimbra, 2013).

According to Hoshin model, senior management maintains that the corporation's strategic goals are simplified to actionable actions at all stages. Middle management is responsible for providing practical guidance to senior management. The frontline supervisors, along with their teams, then translate those "hows" into actionable tasks that will accomplish these overall goals (McLoughlin \& Miura, 2018). Senior management is related with managerial commitment implementing organizational changes and facing new challenges (Sutari, 2015). The concept has a lateral implementation in its original form, which implies that the top management layers define the company's priorities and devise a plan strategy. There may be some variations prior to reaching an agreement. The mid-level management drives the team leaders towards its objectives and the process continues until the individuals at the bottom of the pyramid, are persuaded towards achieving the common goals ${ }^{1}$. In this structure given in Figure 9, kaizen event is used as a method to change an organization's way of thinking, acting, planning and observing the events. This authorizes and empowers staff to make changes, liberating leadership from commands and regulation to micro-manage employees to concentrate on strategies and build innovative approaches. It frees executives to become coaches (Martin \& Osterling, 2007).

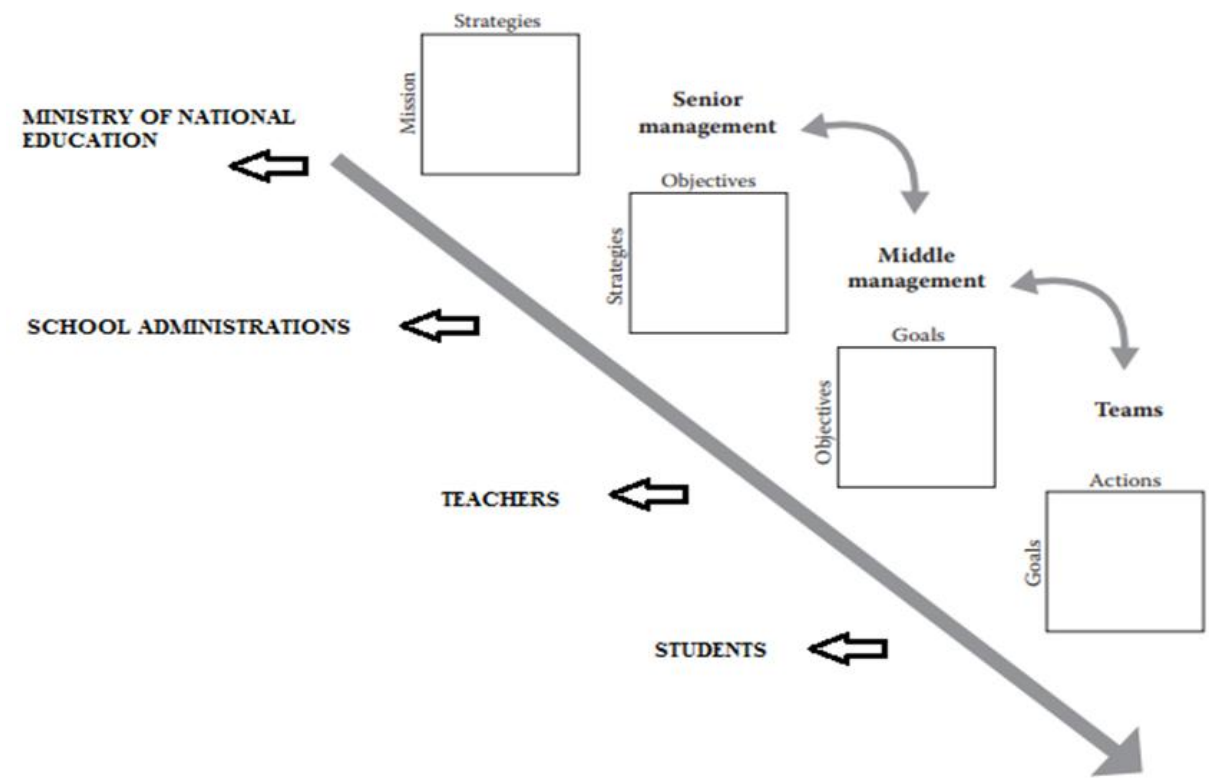

Figure-9. Hoshin model in education (McLoughlin \& Miura, 2018).

Source: McLoughlin and Miura (2018).

${ }^{1}$ https://kanbanize.com/lean-management/hoshin-kanri/what-is-catchball/. 
Finally, just as evaluation of curriculum development, a kaizen event should not be the automatic default answer; instead the deployment methodology should be the least-waste way with requisite quality, delivery, etc. Therefore, summary level flow chart reflecting decision logic for discerning whether a kaizen is appropriate ... or not can be given as Figure 10 (Hamel, 2010).

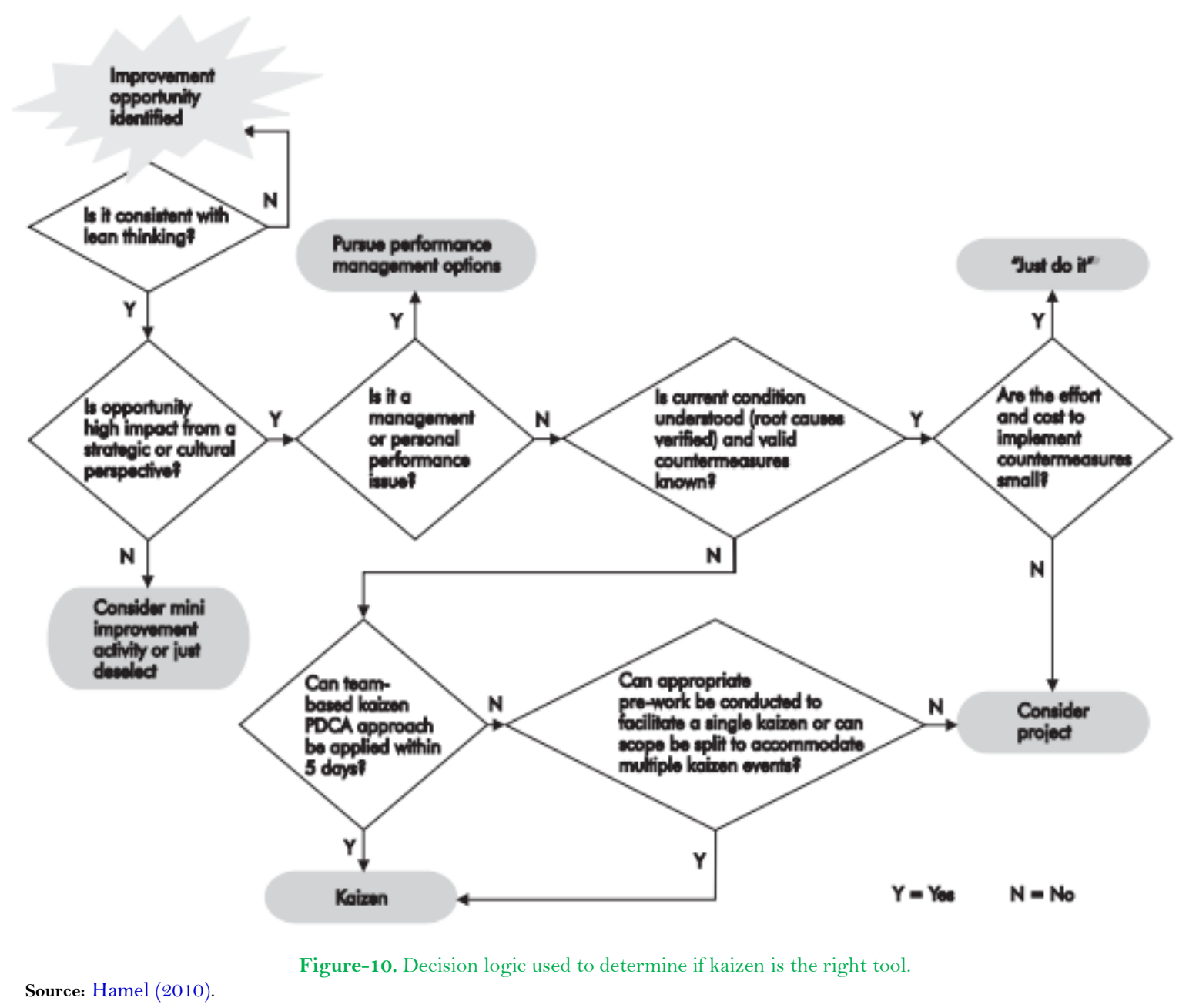

To sum up, a curriculum development model-based Kaizen principle should focus on improvement and maintenance of the curriculum from students to teachers to school administration to ministry of national education so that different agency types gain significance in terms of three levels as student agency, teacher agency and collective agency. In the improvement side, student agency, teacher agency and collective agency have significance for the improvement of the curriculum whereas the actualization of formal curriculum through extra curriculum, operational curriculum and hidden curriculum is important for the maintenance of the curriculum. However, it should be noted that it is just a structure of scheme which is depicted in there, the actualization of this model is only be achieved by the actions of all agents themselves as well as their core principles and aims.

\subsection{Findings for the Third Question as "Why Kaizen Approach is Important for Curriculum Development?"}

Curriculum development is an ongoing process in which curriculums are updated in the context of current needs of society, individuals and states. Many curriculum development models emphasize this feature of the curriculum in similar ways such as Taba's or Taba-Tyler models. However, in practice this feature of continuity doesn't keep in pace with the ongoing changes of the needs as well as qualifications and needs in the future. Therefore, there is a Lucas critique similar to the one in the field of economics in the process of curriculum development. Summarizing it, the argument from Lucas is that the new economic policy will change the current system by impacting market players ' aspirations, because it seeks to measure the impact of this policy on the premise that when a new economic policy will continue, the economic structure is maintained in the same way as the previous one. Although in the needs analysis in curriculum development analytical approach is used to determine the needs according to the possible situations in the future, it can be said that this approach is not actualized beyond popular expectations for the future of education. Therefore, Kaizen approach gain significance because it emphasizes both improvement and maintenance in this regard by presenting students, teachers as well as all stakeholders in the education as actors through depicting dynamic relationships so that curriculum development should be inherently contextualized, including multiple levels in a continuing cycle.

The concept of Kaizen emphasizing continuous improvement was firstly developed in Japan since it was an inexpensive way to improve productivity and to reduce costs in a limited time with extreme resource shortages and also because of the demand of the government, which used continuous methods of development to promote rebuilding in the nation during World War II (Kato \& Smalley, 2015). Therefore, Kaizen approach is important for developing countries such as Turkey in this regard. One of the main mistakes that developing countries do is to bring revolutionary steps especially for social infrastructural elements such as education or more specifically curriculum without waiting the adaptation of those social agents into this new program. This reflects itself in curriculum development as abrupt changes that confuse both students and teachers as well as families in many ways. This can be seen more specifically in many curriculum attempts in Turkey last decades. Actually this problem can be seen also in Ottoman period so that Mustafa Kemal Atatürk who is the founder of modern Turkish 
Republic remarked that "Each Minister of Education, the Deputy [in Ottoman Period] had a program. Teaching has become a mess because of the implementation of various programs in the country's education. "Therefore, although both society and policy makers want to change problems in revolutionary ways, sometimes the structure of problems as well as their complexity make it very difficult for such sudden changes. Because of this reason, Kaizen approach gains significance for changes in order for developing more deep and structural changes in education and other social problems.

Another factor why Kaizen approach is important for education is that it has an holistic perspective giving importance not only the theory but also human agency in all levels. Sometimes, researchers are allured to use concepts such as teacher agency to cure the problems in curriculums and other educational obstacles without considering the concepts' contextual and situational character. Teacher agency, for instance, is very cull concept without student and collective agency. For example, if students are not active participants in educational process or their agency is ineffective in this regard, education will be ineffective no matter how teachers are good or do their best. In historical process, many attempts giving value teacher agency failed because of disregarding other factors such as political conditions, collective agency or even student agency. For instance, Village İnstitutes can be given as the best example for the actualization of teacher agency in Turkey but it is also a good example how such a Project failed because of not considering other factors as well as other agency types. In this respect, Kaizen approach is important both for education and curriculum development because it gives responsibilities not only one factor or agent but all agents and factors in this respect. The cornerstone of Kaizen success is managerial commitment as well as the commitment of all stakeholders. In fact, continuous improvement in the production process is impossible to reach without proper training and education for all stakeholders (Kato \& Smalley, 2015) so that it requires the in service-education for teachers and administrators as well as education of students with curricular activities based on Kaizen principles. Therefore, human resources training increases confidence at schools and helps the schools, teachers and students face the new changes.

\section{Conclusion}

In this research, Kaizen will be examined through document analysis technique in order to reveal core principles of it in the context of curriculum development models as well as proposing curriculum development model based on Kaizen approach. It is expected that the core principles of the Kaizen approach have many similarities and differences with curriculum and development approaches. Especially, the core principles of Kaizen approach as 1- accepting the problem. 2. Selecting projects that do not require a lot of money. 3. firstly looking at your own problems, rather than others. 4. Not being merely focusing on economic interest. 5. determining the priorities 6. applying the circle of planning, applying, checking, taking action cycle 7 . using the correct solution tools. can be incorporated into the curriculum development models in order to make them efficient in many respects.

Kaizen is a tool to control and reduce costs, small but powerful. Unlike other cuts, the quality of the product or service is unchanged by Kaizen. The wellbeing of all stakeholders (administrators, teachers, students) is not compromised by Kaizen. The cost increase for the consumer is not a cover for corporate inefficiency. Kaizen is not a hurried one-time trick. Every employee should be constantly alert for waste of resources in Kaizen organizations which implies extra, null and operational curriculum in the curriculum development process. The system reduces its workforce when it finds a process that doesn't raise the value or quality of the experience (Maruer, 2012).

Kaizen approach in curriculum process is important especially for developing countries to improve productivity and to reduce costs in a limited time with extreme resource shortages.

The kaizen process uses different tools and methods to reveal the problem and then uses official root cause anal ysis and other means to identify and fix the problem at the source (Emiliani, 2006). Kaizen gives value to time and consider it as a strategic resource where many developing countries disregard it for the sake of abrupt and revolutionary changes. Time is one of the scarcest elements in any institution but it is often and largely wasted. Unefficient time use results in stagnation. Materials, goods, information and documents remain inactive, with no va lue added. It is always possible to earn create new curriculums to provide new materials and appoint more people, but time must be wisely used. Once it is consumed, no one has a second chance to reuse it (Kato \& Smalley, 2015). Secondly Kaizen is important because of it holistic approach which takes all agency levels into consideration. In the capitalist age, individual efforts are always appraised and supported by disregarding collaborative efforts and the meaning of individual efforts in the social context. Kaizen gives responsibility to every individual from students to administrators in this regard and not expecting from one party to manage everything to correct current situation. The essence of Kaizen, as emphasized by Imai (1986) is simple and direct:

Kaizen means improvement; nevertheless, it also means involvement including workers and managers. A way of life is assumed at work, at home and within the society.

Therefore, the daily practice of kaizen adds to the organization's identity and drives the transition into a continual culture of improvement - a key component in high performance organizations (Martin \& Osterling, 2007).

\section{References}

Akıl, B. (2013). Application of $5 S$ and Kaizen at public sector. Unpublished Master's Thesis.

Alatas, E. (2015). The effect of Kaizen costing to cost minimization: An application double-glazing business. Unpublished Master's Thesis.

Albayrak, N. (2019). Improving the Kalder quality circle and Kaizen reward evaluation process: Multi-criteria decision making application. Unpublished Master's Thesis.

Arslan, S., \& Akbulut, N. (2018). Hidden curriculum and educational stress. Kastamonu Education Journal, 26(4), 1111 1-1119.

Bal, H. (2013). Qualitative research method. Isparta: Faculty Bookstore.

Biesta, G., \& Tedder, M. (2006). How is agency possible? Towards an ecological Understanding of agency-as-achievement. Working paper 5. Exeter, UK: The Learning Lives Project.

Boca, G. D. (2011). Kaizen method in production management. Paper presented at the International Scientific Conference Young Scientists.

Bozdemir, E., \& Orhan, M. S. (2011). A research on the role and applicability of the kaizen costing method in reducing production costs. Ataturk University Journal of Social Sciences Institute, 15(2), 463-480.

Cakır, S. (2018). Examination of kaizen costing in terms of cost efficiency: Example of accommodation enterprise. Unpublished Master's Thesis. 
Coimbra, E. (2013). Kaizen in logistics and supply chains. USA: McGraw-Hill Professional.

Creswell, J. (2012). Educational research: Planning, conducting and evaluating quantitative and qualitative research. Boston: Pearson Education Inc.

Davis, J. W. (2011). Progressive Kaizen. USA: CRC Press.

Demirel, O. (2009). From program development theory to practice in education. Ankara: Pegem.

Doğanay, P. (2008). Kaizen - human resources development in hospitals with continuous improvement. Master Thesis, Gazi University Institute of Social Sciences, Ankara.

Education Quality and Continuous Improvement Framework. (2018). Retrieved from https://education.vermont.gov/sites/aoe/files/documents/edu-education-quality-and-continuous-improvement-framework.pdf. [Accessed 01.06.2020].

Emiliani, M. L. (2006). Using kaizen to improve graduate business school degree programs. Quality Assurance in Education, 13(1), 3752.Available at: https://doi.org/10.1108/09684880510578641.

Erdeniz, M. (2018). Effects of $5 s$ and kaizen applications on business performance: An application in the furniture industry. Unpublished Master's Thesis.

Floridi, L., \& Sanders, J. W. (2004). On the morality of artificial agents. Minds and Machines, 14(3), 349-379.

Gabbay, D. W., \& Woods, J. (2005). Chapter 2 - practical logic, Editor(s): Dov M. Gabbay, John Woods, A practical logic of cognitive systems. USA: Elsevier.

García-Alcaraz, J. L., Oropesa-Vento, M., \& Maldonado-Macías, A. A. (2017). Kaizen planning, implementing and controlling. USA: Springer.

Goetsch, D. L., \& Davis, S. (2002). Total quality management (2nd ed.). Jakarta, Indonesia: Prenhallindo.

Hamel, R. (2010). Kaizen event fieldbook - foundation, framework, and standard work for effective events. USA: Society of Manufacturing Engineers (SME).

Imai, M. (2014). Gemba Kaizen: A commonsense approach to a continuous improvement strategy. USA: McGraw-Hill Professional.

Imai, M. (1986). Kaizen-the key to Japan's competitive success. New York: Random House.

Jenkins, G. (2019). Teacher agency: The effects of active and passive responses to curriculum change. The Australian Educational Researcher, 47, 167-181.Available at: 10.1007/s13384-019-00334-2.

Johnson, D. W., \& Johnson, R. T. (2015). Social cognitive theory. International Encyclopedia of the Social \& Behavioral Sciences (Second Edition).

Karakaya, M. (2004). Cost accounting. Ankara: Gazi Bookstore.

Kato, I., \& Smalley, A. (2015). Toyota Kaizen methods: Six steps to improvement. New York: Taylor \& Francis Group.

Kaya, Z. (1997). Basic processes of program evaluation process in education. Gazi University, Journal of Industrial Arts Education, 5(5), 59-72.

Kesken, J., \& Ilic, D. (2008). Irrational face of management: Organizational functional disorders and analysis. Ege Academic Review, 8(2), 45 1468.

Klemenčıč, M. (2015). What is student agency? An ontological exploration in the context of research on student engagement (Eds. Klemenčıč,M. Bergan, S. Prımožıč,R.) Student engagement in Europe: Society, higher education and student governance. Council of Europe Higher Education Series No. 20 (pp. 11-29). Strasbourg: Council of Europe Publishing.

Korucu, O. (2013). Effects of Six Sigma and Kaizen methods for improving the quality of final product in manufacturing sector. Unpublished Master's Thesis.

Macit, A. (2018). Kaizen costing in air cargo enterprises and its applications. Unpublished Master's Thesis.

Martin, K., \& Osterling, M. (2007). The Kaizen event planner: Achieving rapid improvement in office, service and technical environments. USA: Productivity Press Book.

Maruer, R. (2012). The spirit of Kaizen. USA: McGraw-Hill Education.

McLoughlin, C., \& Miura, T. (2018). True Kaizen management's role in improving work climate and culture. USA: CRC Press Taylor \& Francis Group.

Misselhorn, C. (2015). Collective agency and cooperation in natural and artificial systems, collective agency and cooperation in natural and artifi cial systems. USA: Springer.

Ogünç, H., \& Doğru, E. (2017). Effect of Kaizen philosophy and total quality management on productivity and cost. Alanya Academic Review Journal, $1(1), 1-13$.

Ozdemir, S. M. (2009). Investigation program evaluation and assessment of training programs in Turkey in Education. Yüzüncü Yıl University Education Faculty Journal, 6(2), 126-149.

PISA. (2018). Retrieved from https://www.oecd.org/pisa/publications/pisa-2018-results.htm.

Posner, G. (1995). Analyzing the curriculum (2nd ed.). New York: Mcgraw-Hill.

Söztanacı, C. (2014). Prevention of occupational accidents in a furniture fabric and improvement of kaizen suggestion system intented to increasing job security. Unpublished Master's Thesis.

Stapleton, M., \& Froese, T. (2015). Is collective agency a coherent idea? Considerations from the enactive theory of agency: Collective Agency and Cooperation in Natural and Artificial Systems (Vol. Springer: Philosophical Studies Series 122, pp. 219-223): USA:

Sutari, O. (2015). Process improvement using lean principles on the manufacturing of wind turbine components-a case study. Mater Today: Proc, 2(4-5), 3429-3437.Available at: doi:10.1016/j.matpr.2015. 07.318.

Terzi, A. (2017). A research on the applicability of the methods of target costing, value engineering and kaizen costing together in the companies. Unpublished Doctoral Dissertation.

Yıldırım, A., \& Simşek, H. (2008). Qualitative research methods in the social sciences (7th ed.). Ankara: Seçkin Publishing.

Yllmaz, S. (2014). Through kaizen - continuous improvement development of human resources in hospital. Unpublished Master's Thesis.

Zeiser, K., Scholz, C., \& Cirks, V. (2018). Maximizing student agency implementing and measuring student-centered learning practices. Retrived from: https://files.eric.ed.gov/fulltext/ED592084.pdf. 